\title{
My dog's the champ: an analysis of young people in urban settings and fighting dog breeds
}

By Saffron Burley (Goldsmiths, University of London)

There is a growing phenomenon of young people in urban areas owning fighting dog breeds, such as Pit Bull Terriers, Staffordshire Bull Terriers and English Bull Terriers. Many people find these youths and their dogs threatening, and many more are concerned that the dogs are being trained to fight, and to deliberately intimidate. As well as the perception of these young people as a threat, there is also a host of anti-cruelty sentiments directed at them. The purpose of this exploration is to examine the origins and characteristics of this phenomenon and the societal responses in regards to it, especially in the context of wider society's historical tendency to assume the worst of this particular group, and the way that many dominant views on this issue echo typical 'moral panic' anxieties. I hope to also reveal the extent of more subtle needs and nuances in the behaviour of these young people and the deeper motivations behind their choice to own and train fighting dog breeds, by using a more sensitive, ethnographic approach to flesh out the picture. I will then apply the understanding gained from this exploration to inform my understanding of the challenges and considerations facing youth and community work in regards to young people, highlighting our aim as youth workers to link our work to broader issues of inequality in society.

\section{Introduction: 'Notting Hill' and dog fighting}

The West London area of North Kensington, referred to by locals and neighbouring communities as Ladbroke Grove (and by wider London as 'Notting Hill'), has a history of diversity. Its appeal has attracted many newcomers to the area-people who enjoy the unique experience of living in amongst Portobello Market and the Notting Hill Carnival. A closer ethnographic examination however, would reveal much about the conflicts and tensions existing among the local groups in this vibrant yet often misrepresented part of West London.

A bird's eye view would show that the area known as 'Grove' by local people is geographically much bigger than the precious few blocks depicted in films like the famous box office hit 'Notting Hill'. The Suttons Estate, the Brunel Estate, and the four estates in the 'Goldborne' ward (to mention just a few), stretch out to form a mass that is roughly twelve times bigger than the central 'Colville' ward, home to the familiar painted Georgian houses and hanging flower baskets that so attract prospective home-buyers. The area retains its 'colourful character' partly because local housing associations such as Notting Hill Trust, Octavia Housing Group and Kensington Housing Trust, and others, enable the continued survival of low-income groups despite the soaring property prices. Interaction between the groups can be observed (a familiar theme of conversation among the young people in my work place is which famous people they have sold drugs to), but also instances of severe alienation, such as an ability among diners in the expensive First Floor Restaurant to 
avert their gaze from the Salvation Army soup queue directly opposite on Portobello Road. The existence of abundance alongside disaffection and poverty arranges the area as a stage for the 'showcasing' of social and/or economic capital. The body language of younger lower-income people is defiant and at times aggressive, especially when coming into contact with those they see as 'outsiders'.

I have had the privilege of an insight into the world of young people and their fighting dog breeds (to whom I will be referring to as 'fight dogs') in this area, having worked consistently with clients who kept the dogs. My working role for some years has been to give key work support (one-on-one mentoring) to residents of Portobello Houseshare hostels, an organisation housing local young people from 'disadvantaged' backgrounds. I have carried out my work with relative confidence, as I am myself an ex-resident of one of the hostels, and am therefore seen by the clients as having inside knowledge of 'hostel life' in the area, lending an added candidness to our conversations. I also carried out qualitative, fieldwork-based research on the phenomenon of dog fighting for my Research Masters in Anthropology project.

The young people I have studied, from mainly West Indian, North African and, to a lesser extent, White European backgrounds, are representative of the local community. These groups notably identify themselves as British (and for the purposes of this paper, I will be using the terms 'British' and 'English' interchangeably). They have in most cases grown up in 'Grove' and are keen to assert their British identity, a partial response to the arrival of newer groups such as East Europeans and East Africans. In 2005, 62\% of local authority referrals to local RPT (Rugby Portobello Trust) hostels were for young people from Eritrea, Somalia, Ethiopia, Albania or Kosovo. In this case resentment is directed towards 'outsiders', as a result of inevitable competition for housing and services. In the case of other 'outsiders', such as wealthy home-buyers, the young people I am studying see these groups as merely 'touristy' types who do not know 'the real Grove' (as put to me by one young person). This view rests on the notion that they are themselves the more established members of the community, and they therefore do not see themselves as 'marginalised' in the way that they might be seen by more privileged groups.

This paper examines the phenomenon of dog fighting in relation to young people in 'Grove'. I will study the low-income status (or 'class') of the group in the same vein as it was seen by studies carried out by the Birmingham School (the Centre for Contemporary Cultural Studies) and the Chicago school, for the characteristics of Ladbroke Grove give rise to elements of 'opposition', 'differentiation', 'resistance' and 'strain' (Cohen 1971, Willis 1997, Hebdige 1997, and Merton 1957). I will argue that 'subculture' theories are highly relevant, but I will go on to explore the complexities of the unique and variable phenomenon of dog fighting, for it defeats any one particular theory, especially since the presence of two sentient 'beings', of two different species, 'complicates the possibility of theorising' (Cassidy 2002:121, on the subject of human-horse relationships). I will examine the perceived image of youth with fight dogs, and the societal tendency to categorise and make 'value' judgements, and will place this within a wider consideration of our entire human impact on the animal world. Lastly, I will search the picture for those aspects that need to be considered for a more realistic understanding, in order to work toward the delivery of effective youth work and a measured response from communities to the potential risk factors. 
I hope to present the issue of dog fighting as worthy of more in-depth enquiry, for this dissertation can only realistically serve as an initiation into the kind of analysis possible with more time and with more data. My study focuses on North Kensington, London, because it was here that I first became aware of the emergence of this phenomenon and carried out my studies. I will refer to data from my Research Methods in Anthropology project, which I gathered through informal conversations and participant observation over a three week period, as I took a one year old male Pit Bull Terrier ('Biscuit') for walks around the area and interacted with young people and their fight dogs (all names have been changed for anonymity). This data, constituting a record of these experiences, takes the form of small cases, or vignettes, which will serve to illustrate the points made. It could be said that this data has been collected as much through my role as a key worker as through my role as a fieldworker, since I already had an established relationship with many of the young people studied, and I found that I used the same familiar manner as I do in my work, made possible by my own 'insider' identity as a community member.

\section{A sociological analysis}

\section{The owning and training of fight dogs: a 'subcultural' activity?}

Let me start with a few vignettes:

Eddie is a young white male and has a male Staff who is three years old. He tells me that he knows a lot of guys who fight their dogs for money, although he hasn't done this and says that he doesn't think he would, although he then says, (laughing) 'only if it was some pitiful lame dog and I knew my dog could win!' On the whole he says that he has the dog for company and protection, although he did 'get into the whole dog thing' through his friends, some of whom take dog fighting really seriously. 'Even if you don't fight them,' he says, 'all the guys on my estate have got one.'

Paul and Malik are 14 and 16 respectively. Neither of them had a dog with them. Paul said that his brother has a Pit Bull, and Malik also said that his uncle had a Pit Bull. Malik showed me some pictures of his uncle's dog on his phone. He then became quite excited and said that his uncle had said that he was going to buy a Pit Bull for him. Paul challenged him about this, and said that he'd been 'saying that since last year'. The two boys began to argue. Malik became quite aggressive with Paul, throwing his arms up in a gesture of defiance, and saying that Paul was lucky he didn't have his Pit Bull yet, because then he'd have to 'shut the fuck up and stay told'. ('Staying told' means to have someone reprimand you and say nothing in return.)

Kadie is a young man from an Irish background. His dog is a Staff. He was very friendly, and told me he would never fight his dog because he loves him too much. He told me a story about a dog trainer up in Kensal Rise; apparently this dog trainer would show how 'good' a trainer he was by getting the dog to hang by his jaw from a plank, and the trainer would hit the dog with a baseball bat while it was hanging there, but the dog would still hold on. This, according to Kadie, was testament to the dog's good discipline. Kadie also told me of a notorious dog up in Kilburn whose name is Demon. Demon has never lost a fight, and has killed over 15 other dogs. Kadie says one of the dogs belonged to a friend of his. He tells me people keep taking their dogs to fight Demon, because Demon's reputation is now 
so huge that the person whose dog eventually beats him will not only make a lot of money but also get 'utmost respect'.

The challenges faced by these young people in terms of income level and social class raises the issue of 'status frustration' in the sense discussed by Cohen (1971) in Delinquent Boys. From this perspective, it is only natural that members of the group would find 'solutions' (Cohen 1971:65), i.e., alternative routes to self esteem. The aggressive appearance of the fight dog culture, approved of and promoted within the group, creates an arena in which status can be renegotiated, and the young person's ego can be fed through this approval which was previously lacking in their lives due to their subordinate position within the class structure. Attendance at schools such as Holland Park (a local secondary school) could conceivably provoke this behaviour, for they are exposed here to some of the most privileged groups in London. Cohen makes the point that young people in the schooling system tend to be compared to one another simply on the grounds of age and sex. No consideration is given to background advantages, and therefore less advantaged individuals simply fight their battle from a subordinate position. He refers to this situation as 'ego involvement' (Cohen 1971:85). By raising our awareness of this aspect of the schooling system, he shows that the unbalanced competition often leaves the working class child with a sense of disillusionment. Unable to attain the same levels of academic success as their middle class counterparts they gravitate towards one another and establish alternative notions of success.

Arguably, owning the dogs provides a route for achieving approval from one another, something to aim for, rather than seeking approval from teachers or more academically successful schoolmates. Cohen looks at this set-up and calls it 'status source' (Cohen 1971:123). The young person has essentially asked themselves 'whose admiration or respect do I value?', and while Cohen acknowledges a young person's sensitivity to a degree about the opinion of others, he shows how a young person is likely to choose a 'status source' in whose eyes he can 'jockey' (Thornton 1997:2) for esteem on an equal footing with other candidates. The fact that the dogs are a source of fear and concern to wider society fits in with Cohen's description of 'delinquent boys' activities as being characteristically non-utilitarian and mostly about being 'oppositional'.

Paul Willis talks about the emergence of this 'opposition' in direct relation to the experience of being judged and labelled by teachers. In his analysis of an 'anti-school' culture, he uses the term 'differentiation' (Willis 1997:125) to explain a process whereby class oppositions are redefined. Having the 'right attitude' (or being an 'ear 'ole' - the term used by the 'lads' in Willis's study to describe those who 'conform' at school) becomes a currency for entrance into the world of success (rather than actual academic ability), and the role of the teacher as the holder of 'knowledge' is dislodged, resembling more that of a 'prison guard' to be regarded with suspicion. The working class boy will consequently style himself as a challenge to this formal paradigm, something perfectly embodied in the owning of a fight dog.

Panning out from the compact picture of the schooling system, we can look at the tendency towards subcultural 'solutions' as what Hebdige calls 'reactive machinery' (Hebdige 1997:402). He proposes that they are doing what they can to challenge the 'symbolic order' which guarantees their subordination by virtue of membership of the 'youth' category. The challenge to this order, according to Hebdige, can be acted out only with those means that are available to the group: 'They are playing with the only power at their disposal — the power to discomfort, the power that is, to pose ... to pose 
a threat' (ibid). While the fight dog is a suitable 'identity symbol' (Hebdige 2005:87) for these purposes, a 'resistance through ritual' also persists, in the spectacular stylistic ways championed by the 'mods' in the 1960s. While the dogs may on the one hand be construed by some as a 'crude conception of masculinity' (ibid:88) (as, ironically, the 'mods' viewed the 'rockers'), the attention to stylistic detail painstakingly carried out by the young person shows an inherited similarity with 'mod' approaches to resistance statements. The expense, the finely tuned awareness regarding expensive breeds, the elaborate training regimes and designer collars are testament to this. The recent opening of a 'pet boutique' on Westbourne Park Road in 'Grove' shows in particular the money-making potential of this phenomenon. Jay is a good example:

Jay is 21 and has had his dog (a Staff/Pit cross) for two years. He got her when she was a pup, and tells me that he takes her health and appearance very seriously. He likes to keep her 'healthy, hungry and angry' and describes some of his elaborate training routines, which include 'springpole', a training prop where the dog grabs the top of an upright pole with its jaws and then hangs on while it is tossed back and forth by the bouncing pole. This exercise strengthens every muscle in the dog's body. He feeds his dog with high-protein foods such as liver, heart and kidneys. Jay has been going to the scenes of arranged fights to 'check out the competition' for the last few months, although he has not actually involved his dog in a fight as yet. $\mathrm{He}$ tells me that a person can make up to $£ 5,000$ at a fight 'if they're serious'.

\section{Utilitarian responses to status frustration}

...behind their frustration is a comparison between what they would like to achieve .... and what they are able to achieve. (Barker 2005:10)

The act of involving one's dog in a dogfight can be highly lucrative ( $£ 500-£ 5,000$ per fight), and the use of dogs as a security measure in businesses such as drug dealing shows that the owning of a dog can be compared with the carrying of a weapon. Breeding the dogs is an especially good way of making money, with high demand and return for puppies:

Roy is a half-Jamaican, half-English 18 year old from the local area. He has a slight Jamaican accent which he tells me is due to having spent school holidays with his dad in Jamaica for most of his childhood. He says that his dog is a 'Pit'. I ask about the fights up at Wormwood Scrubs and he tells me that he goes up there himself with his dog sometimes. Roy tells me that he can get decent money up at Scrubs. He says that his dog is vicious, but not towards people, towards other dogs. I say that I reckon it must be hard, to have an animal you care about, but put it in a situation where it might get hurt. He tells me that not everyone 'cares' about their dog. Sometimes, he says, a breeder might have three or four pups, and only like some of them (maybe the better-looking ones) which they will keep to sell on at a profit. The others (ones which may have breeding 'faults', such as a patch over the eye) would be for fighting, and they can make money for their owner that way.

These aspects of the phenomenon combine to illustrate 'utilitarian' theories, such as those put forward by Merton (1957). He uses a modified concept of Durkheimian 'anomie' to highlight the likelihood of people finding 'illegitimate means' to make 
money when they are exposed to the glorification of material high life, but are 'strained' by the lack of legitimate means to attain it.

The mercenary attitude behind the dog's use in this way brings a strong reaction from other groups in society, a point to which I shall return below. For now I will argue that the motivations for this use are again embedded in social/economic circumstances. Barker (2005) has looked at the challenges young men face in social exclusion settings, and the pressure of attaining idealised versions of 'manhood', and how, in response to these pressures, young men find solutions by 'whatever means necessary' (ibid:8). Mass marketers deliberately target youth (ibid:19), and the so-called 'street wear' labels, such as big sportswear companies, are particularly relentless, adding to the pressure faced by these young people. Barker points to the often lengthy period between leaving school and acquiring a first job, which puts young men in a position where they have, as shown by Merton (1957), no legitimate routes to filling the idealised manhood role.

\section{Beyond a subcultural symbolism}

While 'subcultural' solutions and the ways that these pertain to the fight dog phenomenon make for compelling parallels, these theories tend to reduce the fight dog to a mere object, or symbol. My fieldwork revealed uncountable nuances to the relationships young people form with their dogs, as with any group who interact with animals. Flattening and diminishing these would risk drawing a line around the group, further marginalising and discrediting the knowledge they earn through immersion into this culture. We need to think reflexively, exercising caution before theorising purely in terms of the group's 'class location'. As Passaro (1997:161) notes, 'postmodern power is often maintained by simultaneously creating and fragmenting, inscribing and erasing, collective identities'.

Having noted this, the fact persists that factors existing within the social/economic backgrounds of these young people beg 'solutions'. Disregarding this in examining young people and their fight dogs would be to bypass the fact that membership of any marginalised group manifests itself in the urgency of certain needs, whether these be practical or emotional. I will assert here that fight dogs answer these needs in numerous ways; while a dog provides companionship and comfort for anyone (should they be receptive to it), the young person's fight dog in Ladbroke Grove answers, in addition, very specific needs. Anderson encapsulates the importance of the need on 'the street' to be respected, and above all to never appear vulnerable:

In street culture, especially among young people, 'respect' is viewed almost as an external entity, one that is hard-won but easily lost — and so must be constantly guarded ... the person who is believed capable of 'taking care of himself' is accorded a certain deference and regard, which translates into a sense of physical and psychological control. (Anderson 1999:76)

Scoob expresses this well:

Scoob is a young black male who lives locally. His dog is a Bull Mastiff. His dog and Biscuit were snarling and barking at each other like mad, and he asked me if I wanted to let them fight. I declined the offer, and he smiled and remarked that my dog 'wouldn't stand a fucking chance'. I asked him if he would ever fight his dog for money and he told me that he wouldn't, but at the same time, he said, 'If someone thinks that their dog is better than mine, I'll let them have some, just to let them know. Sometimes you just gotta 
show people, otherwise they'll get too fresh with you. Show them, my dog's the champ. No dog can beat my dog.'

The fight dog can thus be seen as a 'solution' in this sense. No huge departure is made here from subcultural theory, for these are still issues borne out of social circumstance, but they answer the need in each individual to simply survive, physically and emotionally, in an environment which, as Anderson (1999) shows, can be brutal and dispassionate.

Speecher is 19 . He has had his Pit Bull for almost a year. He has never had dogs in his family before. He tells me that his mum is from Trinidad, where it's highly unusual to have a dog in the house. Speecher likes the fact that his dog always lets him know when there is someone 'coming up behind him' or someone approaching his front door. Nowadays, he says, this can be the difference between life and death.

Such an environment is likely to bring about the need for the aforementioned companionship, with the added security of 'unconditional love' (Franklin 1999:85), an understanding of which throws light on more complex, more hidden, yet very distinct needs, and therefore reveals the fight dog as more than simply a symbol in the making of an elaborate (conscious or unconscious; Cohen 2002:lviii) political group statement.

\section{Organising a social world}

\section{Campaigning for respect}

The version of manhood promoted by youth in areas of social disaffection is constructed in such a way as to be attainable by those with illegitimate options as their only route (Barker 2005:18). While much meaning is attached to work status in defining identities in wider society, areas of social deprivation have criminal norms and idealised 'tough and dangerous' roles passed on not so much as an 'alternative' option, but as the preferable one. The names of the 'crews' (or 'gangs') on the North Kensington housing estates exemplify the attitude: the 'Cold Hearted Crew', the 'Show No Mercy Crew' and the 'Heartless Crew' (Bailey 2005:11). Anderson has identified a clear social meaning for young people and their 'campaign' for status on 'the street': 'Might makes right; toughness is a virtue, humility is not' (Anderson 1999:70).

In such a culture there is a penalty attached to acts of submission, and rewards attached to acts of aggression. Young people I have spoken to have made me aware of the importance of this rule, and its application in a world that includes their dogs. To allow their dog to succumb to the 'greater physical abilities of another' (Anderson 1999:70) would be to allow their dog to take on the associated penalty, i.e. the withdrawal of 'respect'. Here we have an example of another more hidden aspect of young people's relationships with their fight dogs, an aspect representing a contrast to Hobbesian (see Peters 1967:144) and suchlike ideas about a simple 'innate lust' for violence, or psychiatric notions of a 'lack of empathy' due to childhood experiences (Zulueta 1993:129). This allows us instead to examine the idea of a dogfight simply as the arena in which the dog defends its honour. The words of Scoob ('No dog can beat my dog ... my dog's the champ') demonstrate the keenness with which a young person might defend the reputation of their dog. Another young man I spoke to, whom I shall call Danny, explained that 'the dog who submits ... loses', thus showing that 
the dogs participate in a social world where there is a hard-line consequence to any kind of 'backing down'.

In the same vein, dogs who continue to fight on even when injured are awarded the revered label of 'gameness' (Cookson 2006). This view of fight dog culture begs the question: How restrictive should we be of the specific meaning of actual 'affection'? Thomas has stated that the dog 'is a creature of its owner's way of life' (Thomas 1983, cited in Franklin 1999:85), and therefore, while these examples are far from 'mollycoddling', there is no denying that they are motivated by the young person's view that the dog 'shares their world', and they evoke a 'socially engaged' attitude (Morris 1998:169); more than simple affection, this is rather more like actual mutual respect. A controversial theme, to which I shall return below.

Showing skill and knowledge of the dogs serves to bolster a 'manly' image further still, and young people will guard their claim to this image by dismissing those less 'qualified', evident in these further comments from Danny:

Danny is a 21 year old black male who moved to Ladbroke Grove from White City three years ago. He tells me that he often feels that he has to 'hold his corner' because people know that he doesn't 'originally come from Grove'. He has two dogs, a small Staff and an English Bull Terrier. He told me that he does sometimes attend dog fights, but says that it's not how it used to be, and that 'too many stupid kids' are getting into dog fighting now. He says they shouldn't really be getting so into it, as 'rolling' (dog fighting) 'is for big men, not fucking kids'. He tells me that just the other day some teenagers were trying to 'act hard' when he walked past with his dogs. One of them had a Staff. When they asked him if he wanted to fight his dogs, he warned them that when one of his dogs fights, the other will too. After that, he tells me, they were too 'shook' (scared) to continue with the idea. He rolled his eyes and said they were 'stupid kids' again.

And these statements from Mark illustrate further that the traditional male hierarchy can be compromised by the presence of fight dogs, which would explain their appeal to younger men in particular:

Mark told me, 'Trouble is, what with all the young boys that are into it now, it's all getting a bit crazy. You could get some kid who's a real prick, but he's got this dog with him, so you can't teach him the lesson he deserves 'cos you'll get your throat ripped out. The thing is, the dog doesn't think he's a prick, the dog thinks he's the coolest guy in the world. That's the thing about dogs.'

It can also be said that the pressure here to attain the image of a 'man' is more severe, as childhood (depicted in middle class stories like Peter Pan or Winnie the Pooh as a magical time of enchantment to be preserved as long as possible) can equal utter subordination in settings of high social exclusion. In the areas described by Barker (2005) and Anderson (1999), the sooner a young boy is old enough to join a gang, the sooner he can 'mitigate a sense of powerlessness and be a part of consumer society', and finally enjoy a sense of protection and the once unattainable sense of being feared: 'instead of me fearing you, you'll fear me' (Barker 2005:40).

\section{The relationship between the young person and the dog}

Looking at the need of young people to assert their status also raises the question of how they can apply themselves to this goal in the sense of acquiring the specialist knowledge and skills to compete. Whereas Cohen has argued that young people of a 
'delinquent' persuasion have 'no time for practice, deliberation and study' (Cohen 1971:30), the example of fight dog culture is one (among many-consider break dancing, rapping, graffiti art, etc.) that demonstrates the need for a high level of commitment. As already said, the training regimes involved in 'bringing on a good fighting dog' are elaborate, demanding much in the way of time and energy. Young people frequently compare their knowledge of dogs in the same way as all groups do who are involved in training animals, and regard the approval of one another as assurance that they have acquired good dog-owning 'credentials' (Cassidy 2002:43). Cassidy identified the same sentiment among the 'lads' in Newmarket racing stables: 'They believe that what they do is important, and between themselves they give credit to each other as experts' (Cassidy 2002:120).

A comparison might be made here with the eighteenth-century 'livestock fanciers' depicted by Ritvo. She looked at the way they would 'toast' each other and their animals at social occasions, and made the insightful point that in doing so they were in fact 'celebrating themselves' (Ritvo 1987:49). All this said, for young men and their dogs, the chance to immerse themselves in a culture in which there is so much to be learnt provides an escape from the difficulties of home lives. The world of the fighting dog can present a whole new adventure for the young person, something typified in the film Bombon (2004), where the main character is given an 'Argentinean Fighting Dogo', and discovers an entirely new world in which he is proud of the admiration the dog receives and is motivated to find out more about this breed that has captivated so many. He wonders at the 'ethos' of the culture; the one occasion when he is bitten by the dog he is told, 'he only did it because he loves you'- $\mathrm{a}$ justification he readily accepts, and he continues to pursue a greater understanding of the enigmatic dog.

Ritvo (1987), Franklin (1999), Thomas (1983) and Serpell (1986) all remark on the indefatigable loyalty of the dog, both in terms of a symbolic and utterly 'British' celebration of fidelity (Thomas 1983:106; more to be said on the irony of this later), and of being a real-life comfort to those who are lonely and uncertain in life (Serpell 1986:72). In my professional work I have found that uncertainty and loneliness is a common condition among young people, accurately shown by the film Kidulthood (2006), where young people in Ladbroke Grove are depicted as struggling with deep conflicts and little trust in those around them, despite being surrounded by 'friends'. It is therefore highly likely that the relationships formed with dogs are more intimate, more co-dependent than observed by outsiders. Serpell's concept of 'pets as panacea' (Serpell 1986:89) reminds us that troubled individuals come to depend on pets for reassurance. Moreover, Franklin points to the deterioration of 'ontological security' (Franklin 1999:84) that has accompanied twentieth-century modernisation and the demise of 'traditional reciprocal relations'. He identifies relationships with dogs as a rare modern example of a truly 'robust and enduring relationship'.

Thus building a relationship with a dog can be seen as a route to being more selfsufficient, in that it frees one from the need for approval from peers. Again, this perspective brings an interpretation of the fight dog as an indicator of choices based on more subtle, emotional needs than those initially discussed. It should also be considered that for many young people in cities, pets offer a rare opportunity to interact with nature, which is proven to bring positive therapeutic results (Anderson and Olson 2006:35). The non-verbal nature of the relationship also enhances the sense of security for the young person, especially as this group is not known for verbal 
expressions of affection. Therefore the exact nature of the relationship does not present itself openly to observers.

While the above perspective of the dog as companion (soul-mate almost) might divert us from arguments about 'ego involvement' with peers (as stated by Cohen 1971), or the urgent emotional or even practical needs stemming from 'street life' (as seen by Anderson 1999 or Barker 2005), it is still understandable from this viewpoint that the choice of said dog would be the fight dog. Here are the species of dog which most resemble the typical 'hot-blooded', low-income, urban youth: body language alert, strong and ready. The shape is solid, yet agile, and many youths can even be observed to have the same slightly bow-legged walk. Thomas has remarked on the tendency to pick dogs with 'qualities that are one's own' (Thomas 1983:106). Ritvo made similar assertions about the historical liking for the 'Durham Ox' among wealthy landowners, typically 'elegant and ample', an example of the way, she argues, that animals often 'embody the values of their owners' (Ritvo 1987:46).

There is the issue of exactly how this relationship manifests itself; Franklin (1999:86) noted that the pet will typically retain its 'childish' relationship to the owner throughout its life, ensuring the human's role as the leader of the two. This, combined with the association of the dog with one's own 'sense of self' (highlighted above), brings much deeper elements to an analysis of the fight dog and its purpose in the young person's life. Among the young people I have worked with, a floundering 'sense of self' and the rarity of chances to 'lead' are pertinent issues, as prescribed roles for many of these youth are typically subordinate, in the home, school or workplace.

Ritvo might assert the claim that all pet keeping is 'ego involved', and that keeping a 'dangerous animal' offers a person 'a project of domination' (Ritvo 1987:6). She speaks of animals as 'models for human subordinates', in that they epitomise appropriate relationships between masters and subordinates. One can speculate with good cause here about the largely non-white, invariably subordinate status of the group of youths in question, in the context of British history. Eighteenth-century paintings of white aristocracy often included a small black child, looking up adoringly at their 'master', 'as a pet would' (Tyson 2006). The poetic irony of the modern fight dog and its utter devotion to its new young master is undeniable. Perhaps the dog can in this sense be seen as having transcended beyond existence as a 'solution', 'symbol' or even 'companion', but can in fact be admired here as a simple 'work of art', a contemporary rebuke to our colonial history.

\section{Fight dogs: taking their prescribed role in societal relations?}

The very categories into which animals were divided often signalled important distinctions and oppositions. (Ritvo 1987:4)

The fight dog has a rich and honourable history with members of the working class. It is a useful creature, willing and able to protect a person in public and guard one's home and possessions. Arguably, in spite of the 'paternalistic' society in which we supposedly live, many lower-income groups have little faith in the ability (or the inclination) of the police to protect their interests, leading many members of these groups to seek other means of protection. Higher class groups, on the other hand, have tended towards breeds more for their appearance, not for their ability to be of any actual use. 'Cachet' breeding particularly highlighted the element of decadence, evident in the fact that an expensive animal, one that served no particular use, whilst 
costly to raise and keep, was especially celebrated: 'The expense of high stock breeding guaranteed its continuing cachet ... they would be rewarded mainly in prestige, a coin few could afford to accept' (Ritvo 1987:54).

Young people can be observed as both interacting with, and rebelling against, many of these attitudes of the animal breeding world. The expensive feeding and grooming mentioned above exemplifies the attitude of 'cachet' breeding, with the added twist that these dogs were never traditionally appreciated for their appearance. The boundaries are pushed further still by the fact that some daringly individual youths, those who are utterly unafraid to make a new statement, have recently been observed proudly walking around the same domain as their fight dog peers with elegant breeds such as the Dalmatian (something I have only observed on two occasions - in both cases the youths also chose a distinctive style of dress). The point here is that the pride in being distinctive is on the one hand an echo of those old attitudes, while on the other hand there is still no denying the rebelliousness of fight dog culture, especially as owning many of the Pit Bull dogs is an illegal act. (In the UK, the Dangerous Dogs Acts of 1989 and 1991 state that all Pit Bulls after November 1991 should either be terminated by a vet, for which $£ 25$ compensation would be awarded, or should be exempted through licensing, neutering, and the tattooing of registration numbers-in which case all Pit Bulls should be owned and handled by a person aged over 16).

\begin{abstract}
Jordan is a 19 year old mixed race boy from the local area. He didn't have a dog with him, but called me aside and discreetly asked if Biscuit was a Pit. He advised me to be careful, as the police are on the lookout for illegal dogs, and told me that his friend had recently had his dog taken from him by the RSPCA. He confided in me that he thinks his friend's neighbours were the ones who informed the police that the dog was there. 'You can't trust anyone nowadays...' he said. I asked him if his friend ever used to fight his dog, and he said no, but he should have done, it was an amazing dog and it could have won every fight.
\end{abstract}

So, here we make something of a return to subculture theories and must firstly make the following concession: while there are many aspects of the relationship with the dog that cannot entirely be catered for by such theories (as we have seen), we need to look at the seductive appeal of rebellion, of 'opposition', of bravado, and must note that these elements are very much present in the attitudes and motivations behind acquiring the dogs, similar to the motivations of modern-day 'chavs' for acquiring their 'Burberry', or 'mods' for acquiring their scooters (Hebdige 2005). Secondly, the fact that the dogs already have a long history with the working classes, and have long been revered for their strength and usefulness, could be seen as a rebuke to the historical reign of the British upper classes and a deliberate sign of affiliation with the traditions and sentiments of the former.

\title{
'We are fully committed to dealing with this problem': an analysis of societal responses
}

This title is taken from Met News Bulletin (14.05.2006). The perceived image of the group in question seems to be one of 'brutality' and, remarkably, of 'un-Britishness'. Objections range from fear and concern that the dogs are not being cared for, or controlled properly, to extreme outrage at the idea of the dogs being used for fighting. While it is not my intention to argue against these claims, it is worth looking at some of the inherent paradoxes existing within wider society's view that it has a duty to 
control and regulate the fight dog phenomenon. Firstly there is the concept of 'cruelty', and how it is applied by other groups. I will look at this first and then move on to a discussion of the current climate of 'respectable fear' (Pearson 1983) surrounding the issue.

On the concept of cruelty, I would like to begin with the rather obvious example of fox-hunting, which has now been illegal in Britain since February 2005, though hunts are in action all over the British Isles, partly because laws prohibiting the hunt allow for negotiation. (It is still legal to ride out in large numbers, and to shoot foxes which are deemed as vermin. Hunts will set off carrying a gun, but if a fox is killed by dogs, then 'unintentional fox killing' can be argued [Dear 2005].) The similarities between the two spectacles of dog fights and a fox being set upon by hounds are irrefutable, and the point of distinction more concerns the class locations of the two groups involved. On occasion when a 'huntsmaster' (an honorary position often given to the eldest son of the 'laird') has to defend himself in court against the flouting of the antihunt laws, he invariably has the articulacy and presentation skills to avoid severe penalties.

Horse racing is another area worth consideration, for while the safety of the horse is obviously at risk (horses regularly die on the course; Cassidy 2002:125), less obvious features of the racing world could be viewed as bringing about relentless suffering. Cassidy's exploration reveals a certain 'brutality' in the lifestyle and treatment imposed upon the jockeys. The so-called 'gentleman's sport' (ibid:64) involves a weight control programme for the jockeys referred to as 'wasting', which, as the term implies, is 'potentially debilitative' (ibid:23). In addition, investigations into safety on the racecourse are carried out with the 'foregone conclusion' that the dangerously fatal potential of the act is already 'a given'.

Serpell's (1986) chapter on 'Of pigs and pets' reminds us that intensively farming animals for meat production imposes immeasurable suffering. In his depiction of the short life of a pig from birth to slaughter he describes torturous conditions, the brutal clipping and docking of teeth, ears and tails, and castrations (all without anaesthetic), and informs us of PSS (porcine stress syndrome), suffered by many of the pigs, along with the terrifying ordeal of their transportation to the slaughterhouse, and the 'untold horror' of the actual act of slaughter (ibid:10). Serpell understandably takes firm note of the irony that we who fuel the demand for such an industry are the same people who lavish affection on our pets; the reason this state of affairs is so disquieting is that apparently we simultaneously hold two contradictory and incompatible sets of moral values.

Ethnographer Morris (1998) may well note that, as well as the cruelty pigs suffer at our hands, a further question relates to the sheer and utter 'spiritual' disrespect endured by these animals. Morris' study of people's relationships with animals in rural villages in Malawi reveals a 'practical' or chibwenzi attitude: 'a socially engaged attitude ... recognises the fundamental affinities between humans and mammals as living beings who share a common world and are often in competition' (ibid:169). Morris shows that an example of this attitude is expressed in the strong empathy that is experienced between humans and the hunted mammal. Thus, the perhaps controversial question is raised of whether or not a dog involved in a fight has been subjected to a comparable level of 'spiritual' neglect or abuse as other animals.

A thought-provoking instance in the film Amores Perros comes when an old man who is caring for an injured fighting dog returns home to find that the said dog has killed 
all of his other beloved dogs. Anguish stricken, he holds a gun to the dog's head in a desperate state of grief and anger, but eventually chooses not to shoot it on what seems to be an understanding of 'the nature of the beast'. While the 'nature' of the pig in Serpell's (1986) study is undeniably flouted, and its life, like that of the fox or the Newmarket jockey is entwined with experiences of stress, and suffering, these are simply facts of life in 'civilised' western society. The 'outrage and disgust' that Serpell describes at the 'mistreatment' of pets is simply embedded in ideas about one's own 'respectableness' in opposition to the 'other' group's 'monstrousness'.

We need to consider the context and location of 'anti-cruelty' sentiments; i.e., who decides what cruelty is? Ritvo (1987) examines the rise of anti-cruelty sentiment in the nineteenth century and makes the link between this particular form of philanthropy and British 'high class' concerns. She shows amusement at an announcement that an 1841 RSPCA (Royal Society for the Prevention of Cruelty to Animals) meeting had been 'very fashionably attended' (ibid:129), showing how frequently value judgements were made, motivated not by an all-encompassing understanding of the human impact on the animal world, but by a sentiment seeded from new class ideals: a new-born link between upper class benevolence and kindness to children and animals (ibid:132). She shows that the concept of 'cruelty' is relatively recent (the SPCA, Society for the Prevention of Cruelty to Animals, was not started until 1824; ibid:126), and informs us of the insatiable early-nineteenth-century interest in cock fighting, rat killing, bull baiting and wild animal baiting. She then shows how the later notions of 'decency' were used as 'instruments of marginalisation' (ibid:130) whereby those who did not comply could be accused of 'brutality' and 'un-Englishness', and consequently excluded from the national community.

A host of arguments exist implying that young people with fight dogs present a threat to the 'British way of life', a typical worry being the notion that these young people have too much time on their hands and that parents and other authority figures are too lenient with them. Pearson (1983) documents a wealth of loudly expressed anxieties throughout the nineteenth and twentieth centuries, all of which echo not only the idea that our youth are wallowing in too much time and freedom (courtesy of a foolishly 'liberal society'), but that their behaviour is a threat to 'Britishness' - a way of life that could previously be taken as a measurement for all things 'civilised' and used as an example of 'moral fibre'.

The public cry of 'how can we protect ourselves?' (also a consistent theme in Pearson's 'Hooligan'; see pictures of the 'garrotting panic of 1862', Pearson $1983: 139,141)$, leads us to consider, firstly, that the pattern of behaviour most remarkable is that of the 'audience' rather than that of the 'actors'. Cohen has laid out the 'inventory' (Cohen 2002:37) of the stages of societal reaction to any phenomenon that is deemed as a 'threat' or 'disturbance' with the following characteristics: (i) orientation, (ii) images, and (iii) causation. The 'concern' in wider society that 'these boys with their dogs' are 'brutal' and that their behaviour is 'a danger to decent society', along with an existing negatively perceived image of the group, and of course, the idea that the problem lies with a 'permissive society' (ibid:163), is all in perfect keeping with Cohen's inventory. Secondly, these factors reveal the concept of 'Britishness' as one that is relentlessly appropriated to push already marginalised groups to the fringes of society. 


\section{Challenges and considerations for community and youth work}

In conclusion, let me return to the question of the relationship between my role as fieldworker and my role as youth worker. Here I wish to explore what my broadly ethnographic approach towards the phenomenon of fight dogs can contribute to my work with youth. First of all, in fight dogs we have the valuable opportunity to look at the issues affecting young people in what perhaps constitutes their most uncompromisingly naked form. The dog, as we have seen, is a 'creature of its owner's way of life', and so its behaviour, its well-being and the context in which we perceive it can all be seen as the 'voice' through which the young person's biography speaks. The data from my Research Methods in Anthropology project revealed the breadth and scope of the different relationships young people have with their dogs, but of particular significance is that since taking an interest in the dogs I have found it easier to engage with young people. Freire (1996:27) notably commented that the process of humanisation (out of oppression) can only be restored by those who are truly 'solidary' with the oppressed. Taking steps to understand something/someone they have fallen in love with can be a step to the realisation of such a role.

Just as the dogs answer certain needs for the young person, they are an indicator of needs, which must be recognised and understood by youth workers if our work is to be realistic, holistic and relevant. Rather than seeing the dogs as external to the young person, drawing the dogs into the centre of our understanding and seeing the motivations behind the choice to own the dog can aid us in directing and focussing our work. The distinct need for companionship (as shown by Serpell 1986), or the lack of 'ontological security' (Franklin 1999), or the choice in some cases of the young person to deliberately present as aggressive (Anderson 1999), all indicate aspects of the highly pressurised and rapidly changing urban 'terrain' through which young people are expected to negotiate their way, in addition to having to grapple with conflicting expectations from society. As already said, one of the consistent public beliefs about youth is that they should not have free time, or a disposable income (Pearson 1983:57). They should be humble, grateful for any occupation (or charity) they can get, and respectful of adults at all times, regardless of whether they are treated badly. The New Labour 'Respect' agenda seems to echo these sentiments almost exactly (see e.g. interview with New Labour's Louise Casey, entitled 'No More Misbehaving'; Wintour 2006). Practitioners need an all-encompassing understanding, and the issue of fight dogs can aid us in our learning, as they indicate the presence of loneliness, of vulnerability, and of the distinct lack of trust in authorities to protect or to empathise with the needs of youth. Moreover we need to be aware of the constant double standards imposed on this group, highlighted so neatly by the issue of fight dogs, in regards to what it means to be 'civilised', to be 'British', or to be 'brutal', and challenge these, and support young people in challenging these.

We are in a position to advocate for groups who have been stigmatised by society, but more importantly to encourage them to advocate for themselves. A love for dogs can be a link to wider society; the 'pony club' may, after all, be typically attended by members of another class, but the point of significance is that it is a social event, bringing interaction, discussion and creative output, all of which need to be encouraged and celebrated in work with young people. I discovered in my fieldwork that a dog invites friendly engagement from strangers. Dogs are social catalysts, representing positive potential for youth work. By encouraging walks in parks instead of in the immediate area, interaction with other groups can be attained, thus dismantling stigmas and widening the social experience of the young person. On an 
interpersonal level, the actual relationship between the dog and the young person should be recognised by both the young person and the worker as a medium through which learning how to give love, and to accept love, can take place (Serpell 1986:103). For within this relationship, the importance of responsibility, and of parenting, can begin to present itself to the young person. In many cases, this may be the first time the young person has fully experienced either.

This said, we need to remain centred in youth work aims, and avoid much of the 'passivity' implied by relativist arguments, so that we can take on board the valid concerns for the welfare of both the dogs and the young people. Young people lose valuable opportunities because of attachment to their dogs, such as access into buildings with careers advice services and workshops, or even just the chance to socialise and explore opportunities freely without the difficulty of accommodating a dog. In some cases, even when they have permanent and secure accommodation, young people jeopardise their tenancies because of their dogs:

Hanif lives on Dalgarno estate, which is one of the larger estates in the area. He says that walking his dog (a large English Bull Terrier) is a bit of a chaotic experience, because there are so many fight dogs on the estate that there's always a lot of snarling and 'craziness' before he gets out on the street and walks up to Wormwood Scrubs, where it's quieter. There are still lots of dogs up there, but there's enough space for all of them to walk and train their dogs in relative peace. 'I don't know how much longer I'm going to be living on this estate though,' he says. 'The landlord has got it in for me because I've got a dog and it's a breach of tenancy...' I ask him if he would get rid of the dog, and he laughs as though this is a crazy idea. 'I'd never get rid of him! Even if I have to lose the flat!' He then laughs again and says that he could always set the dog on the landlord if things get really bad.

In my time at RPT two young people declined a hostel place because they would not be allowed to keep their dogs, thus turning down a chance to make use of a service specifically geared to meet their needs. Having said this, many young people in the hostels keep their dogs in their (often very small) rooms, which is stressful for the young person, the dog, and their neighbours, and although this is not allowed, it has been able to continue because the organisation does not have staff or resources to sufficiently tackle the problem. There have been a number of incidents in the hostels involving fight dogs, and there is talk of installing CCTV to prove that the dogs are living there full time. It was decided that RPT did not have the funds for this expensive measure. Without proof, however, the young people cannot be accused of breaching their tenancies and the issue of the dogs persists. The same applies to community centres and youth clubs, putting already stretched organisations under added pressure, not to mention that groups in the community lose sympathy for the aims of organisations if they feel that they are tolerating 'animal cruelty' or if they associate the clients with an image of 'aggressiveness'.

In short, the phenomenon of fight dogs also has a discernible impact on youth workers, and in my work I have felt the tension that surrounds the youth who own or wish to own dogs. Many of the studied young people are not at a stage in their lives where they are able to provide stable and comfortable surroundings for the dogs. As a youth worker I often feel the need to try to encourage young people to wait before getting dogs until they are able to accommodate them in stable environments. But, apart from the irony that the young people themselves are struggling to remain emotionally balanced in hostel or foster-home environments, many of them will be 
housed on estates where there might still be elements of the chaos they experienced in their hostels (as illustrated by Hanif above), serving as yet another reason to link youth work to broader issues of inequality, issues fed into by processes of discrimination that also lend themselves to the value judgements, assumptions and moral panics I have discussed.

We are prone to misconstructions in keeping with a historical tendency to assume the worst of this particular group. The less visible triumphs and the subtler potentials that exist within this union of young person and dog do not present themselves immediately to society or to community and youth work. Despite the value of these elements of the relationship formed between the young person and their dog, and the youth worker's potential to capitalise on this, the owning of the dog does little more in society than bolster the image of the young person as a 'problem'. The idea of the dog purely as a sign of the young person's oppositional stance rests partly on a value judgement that this group is incapable of forming meaningful relationships with animals, and partly on the implication that the endeavour is a 'phase', a reaction to circumstances, which might pass either when the circumstances change, or when the young person acquires more in the way of education, material success, or more of a 'civilised' understanding.

There is much to be learned from embracing the complexities of this story with a sensitive, thoughtful ethnographic approach to flesh out the picture. As Cohen (1971) noted, young people do care to a degree about the way they are seen in society, and this analysis has shown much of the way they are morally 'panicked' about, viewed as a sign of a deteriorating nation, believed to be a menace if they have the 'luxury' of a bit of free time, or a bit of money. The loyalty, protection and utterly ungrudging devotion of the dog both symbolise and answer the obvious resulting needs of the young person.

\section{References}

Anderson, Elijah. 1999. Code of the Street: Decency, Violence and the Moral Life of the Inner City. New York and London: WW Norton.

Anderson, Katherine L. and Myrna R. Olson. 2006. The value of a dog in a classroom of children with severe emotional disorders. Anthrozoos 19(1), 35-49.

Bailey, Shaun. 2005. No Man's Land: How Britain's Inner City Youth are being Failed. London: Centre for Young Policy Studies.

Barker, Gary. 2005. Dying to be Men: Youth, Masculinity and Social Exclusion. London: Routledge.

Cassidy, Rebecca. 2002. The Sport of Kings: Kinship, Class and Thoroughbred Breeding in Newmarket. Cambridge: Cambridge University Press.

Cohen, Albert K. 1971 [1955]. Delinquent Boys: The Culture of the Gang. New York: The Free Press and Macmillan.

Cohen, Stanley. 2002. Folk Devils and Moral Panics, $3^{\text {rd }}$ ed. London: Routledge.

Cookson, Richard. 2006. Across Britain, a clandestine world of cruelty lives on. The Guardian Special Report, 3 January. 
Dear, Paula. 2005. Out with the anti-hunt monitory league against cruel sports. BBC News Oxfordshire, 10 March.

Freire, Paulo. 1996. The Pedagogy of the Oppressed. London: Penguin Books.

Franklin, Adrian. 1999. Animals and Modern Cultures: A Sociology of HumanAnimal Relations in Modernity. London: Sage.

Hebdige, Dick. 1997. Posing... threats, striking... poses: Youth, surveillance, and display. In The Subcultures Reader (eds) Ken Gelder and Sarah Thornton, 393-405. New York: Routledge.

--------. 2005 [1976]. The meaning of mod. In Resistance Through Rituals: Youth Subcultures in Post-War Britain (eds) Stuart Hall and Tony Jefferson, 87-96. London: Routledge.

Morris, Brian. 1998. The Power of Animals: An Ethnography. Oxford: Berg

Passaro, Joanne. 1997. 'You can't take the subway to the field!' 'Village' epistemologies in the global village. In Anthropological Locations: Boundaries and Grounds of a Field Science (eds) Akhil Gupta and James Ferguson, 147-162. Berkeley: University of California Press.

Pearson, Geoffrey. 1983. Hooligan: A History of Respectable Fears. London: Palgrave Macmillan.

Peters, Richard. 1967. Hobbes. London: Penguin.

Ritvo, Harriet. 1987. The Animal Estate: The English and other Creatures in the Victorian Age. Cambridge, Mass.: Harvard University Press.

Serpell, James. 1986. In the Company of Animals: A Study of Human-Animal Relationships. Cambridge: Cambridge University Press.

Thomas, Keith. 1983. Man and the Natural World: Changing Attitudes in England 1500-1800. London: Penguin.

Thornton, Sarah. 1997. General introduction: What is a subculture? In The Subcultures Reader (ed.) Ken Gelder and Sarah Thornton, 1-10. London: Routledge.

Tyson, Cathy. 2006. The black eighteenth-century. Television programme on BBC 4, 3 July, 9pm.

Willis, Paul E. 1997 [1977]. Culture, institution, differentiation. In The Subcultures Reader (ed.) Ken Gelder and Sarah Thornton, 121-129. London: Routledge.

Wintour, Patrick. 2006. No more misbehaving. The Guardian, 26 July.

Zulueta, D. 1993. Felicity from Pain to Violence: The Traumatic Roots of Destructiveness. London: Whurr Publishers.

\section{Films}

Amores Perros. 2000. Guillermo Arriaga and Alejandro Gonzalez Inarritu.

Bombon. 2004. Carlos Sorin and Juan Villegas.

Kidulthood. 2006. George Isaac, Mendaj Hudsa and Noel Clarke. 


\section{About the author}

Saffron Burley did her MA in Applied Anthropology in Youth and Community Work in 2006 at Goldsmiths. She chose to write her dissertation on the subject of young people and fighting dog breeds after four years' experience in youth work in North Kensington, London, where she first became aware of the phenomenon. Since completing her MA she has been working with young people helping them to complete the Duke of Edinburgh Award in Kensington and Chelsea. She can be contacted at saffron.burley@,ntlworld.com 